\title{
Fotografía forense de los protocolos de fotografía forense Riobamba, provincia de Chimborazo-Ecuador
}

Forensic photograph of the protocols of forensic photography Riobamba, province of Chimborazo-Ecuador

Fabio Nelson Rodríguez Ortega ${ }^{1}$

Recibido: 10-02-2019 / Revisado: 15-02-209 /Aceptado: 04-03-2019/ Publicado: 14-06-2019

\begin{abstract}
.
DOI: https://doi.org/10.33262/cienciadigital.v3i1.1.369

Forensic photography at the scene of the crime is partly a collection of physical evidence $(\mathrm{EF})$, the $\mathrm{EF}$ is captured in image format and is permanent over time, therefore according to the protocol of management of the place of events and / or judicial police manual of Colombia, it is necessary to document under technical principles the scenario and absolutely all the EF found in it; understanding that photography as lasting memory is the evidentiary link between the EF itself, the scene of the crime and the criminal conduct investigated. This documentary process does not always occur in the investigations in Colombia, Ecuador and other countries, a very clear example is observed in the cassation claim (Process No. 32193 of October 21, 2009), where the inefficiency in the documentation of $\mathrm{EF}$ is exposed; situation in which it is alleged that there is no photographic documentary evidence of the EF collected at the scene and this affects the taking of judicial decisions. Because of this, this document aims to illustrate some technical elements not detected in the FNG's photography protocol, showing, in a constructive spirit, considerations to be taken into account in current forensic photography processes.
\end{abstract}

Keywords: photography, videography, metadata, research, reconstruction.

\section{Resumen.}

La fotografía forense en la escena del crimen es en parte una recolección de evidencia física (ef), la ef se encuentra capturada en formato de imagen y es

\footnotetext{
${ }^{1}$ Unidad de Investigación Forense y Criminalística Profesional UIFCP, Colombia, uiforensicol@ gmail.com /
} UIF_colombia@hotmail.com 
permanente a través del tiempo, por ello de acuerdo al protocolo de manejo de lugar de los hechos y/o manual policía judicial de colombia y otros países, es necesario documentar bajo principios técnicos el escenario y absolutamente toda la ef encontrada en el mismo; entendiendo que la fotografía como memoria perdurable es el enlace probatorio entre las ef en sí, escenario del crimen y la conducta criminal investigada. Este proceso documental no ocurre siempre en las investigaciones en colombia, ecuador y otros países, ejemplo muy claro se observa en la demanda de casación (proceso no 32193 de 21 octubre del 2009), donde queda al descubierto la carencia en la documentación de ef; situación en la cual se aduce que no existe prueba documental fotográfica de las ef recaudadas en el lugar de los hechos y esto afecto la toma de decisiones judiciales. por lo anterior este documento pretende ilustrar algunos elementos técnicos no detectados en el protocolo de fotografía de la fng colombiano, mostrando con ánimo constructivo consideraciones a tener en cuenta en los procesos de fotografía forense actual.

Palabras clave: fotografía, videografía, metadatos, investigación, reconstrucción.

\section{Introducción.}

Desde la entrada en vigencia de la ley 906 DE 2004 hasta la fecha 2018 en Colombia, han surgido el Manual de Policía Judicial (2006), Manual Único de Criminalística (2016) y el Instructivo para la Documentación Fotográfica Digital en la Investigación de Delitos Sexuales y Lesiones Personales del Instituto Nacional de Medicina Legal y Ciencias Forenses, que disponen los requerimientos técnicos fotográficos en materia criminalística en Colombia, protocolos que revelan la importancia de un correcto procesamiento de escena y documentación de la misma desde la topografía, fotografía forense, entre otras áreas técnicas; pero la falta o no aplicación de procedimientos y ejecución de documentación en la fijación de EF, así como no aplicación de los protocolos en fotografía forense, afectan de forma directa la administración de justicia en su toma de decisiones y el contexto técnico - jurídico en el que se encuentran muchos procesos investigativos en Colombia.

Con lo anterior nace una gran interrogante desde la lógica y el principio de comprobación científica, la cual impera en si tiene suficiente valor probatorio determinada Evidencia Física (EF) y/o Elementó Material Probatorio (EMP) allegado a un proceso penal sin poseer ninguna documentación fotográfica, videográfica o soporte topográfico que la relacione directamente con el lugar de los hechos contrario a la ley; y como es que sin lo anterior, los administradores de justicia toman sus decisiones bajo el concepto de "fuera de toda duda razonable". Por esa razón la documentación fotográfica y videográfica debe ser organizada y orientada en una progresión general a lo específico, documentación técnica gráfica que plasma la situación original del lugar de los hechos y toda la EF relacionada con el mismo, de esta manera se lleva un registro visual soportado completo 
del hecho para asegurar una cabal investigación, procesos de reconstrucción de los hechos y un subsecuente procesamiento de información que orienta la toma de decisiones administrativas o judiciales.

Conocemos la fotografía y videografía forense como herramientas científicas periciales, donde el profesional tiene que perennizar la EF dentro del lugar de los hechos procurando ser muy cuidadoso, analítico, observador, minucioso, organizado; sin olvidar documentar ningún detalle pues podría llegar a tener un valor radical en procesos de reconstrucción de los hechos. Toda EF siempre es importante en cada caso máximo cuando es fundamento para soportar la relación de la misma con el lugar de los hechos, proceso que debe respetar las políticas y parámetros técnicos en materia de investigación criminal en Colombia; con la aplicación de procedimientos, protocolos de recolección y entrega de información fotográfica, técnicas, instrumentos y métodos de documentación fotográfica y videográfica actualizados aplicados al ámbito forense.

\section{Metodologia.}

La primera etapa en este proyecto investigativo fue la observación de los protocolos de fotografía forense de Colombia y otros países emanados por instituciones estatales y el protocolo de la Unidad de Investigación Forense y Criminalística Profesional (UIFCP), laboratorio privado de ingeniería forense y reconstrucción de muertes violentas de Colombia. De los anteriores documentos se detectaron grandes diferencias, las cuales imperan en errados conceptos técnicos de manejo de información fotográfica y procedimientos de documentación y/o fijación de EF/EMP y del lugar de los hechos. Ejemplo de estas variables identificadas son:

Concepto errado de toma panorámica: según (Fiscalia General de la Nación, 2005). "Panorámicas (larga distancia): Tomas globales, que se usan con fines de localización y muestran el aspecto general del lugar tal como se encontró. Se deben hacer por lo menos cuatro tomas en ángulos diferentes."

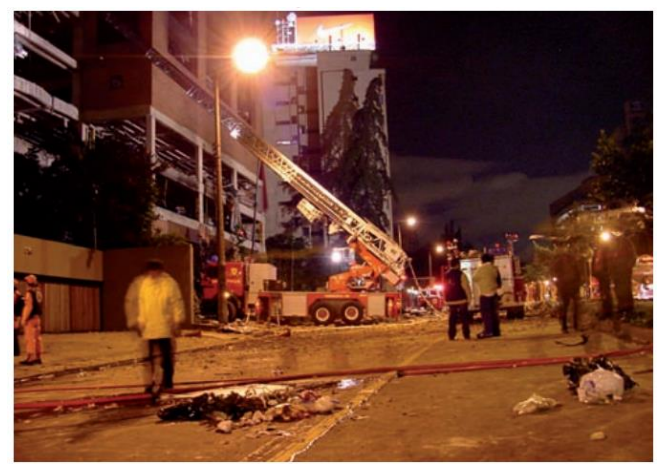

Figura 1. Panorámica según FGN, recuperado del manual de criminalística de la Fiscalía-Colombia.

Revisando los principios técnicos de la fotografía panorámica dados por la FGN se encuentra que esta definición es errada, constriñe la verdadera naturaleza y umbrales de 
la fotografía en formato panorámico donde existen precedentes de la misma que establecen las características y los principios técnicos de este formato gráfico.

Definición de panorama: según (Diccionario Real Academia Española). "Del ingl. Panorama, título de un largo lienzo panorámico del pintor inglés R. Barker, 1739-1806

Antecedentes de la fotografía en formato Panorámica: una de las primeras representaciones gráficas en formato panorámico fue realizada por Joseph Punchberger en el imperio Austro-Húngaro en 1843, utilizando daguerrotipos o placas metálicas relativamente largas. Luego por Friedrich Von Martens en Alemania el año 1844, surge una cámara panorámica más exitosa y con ello un mejor desarrollo de la técnica.

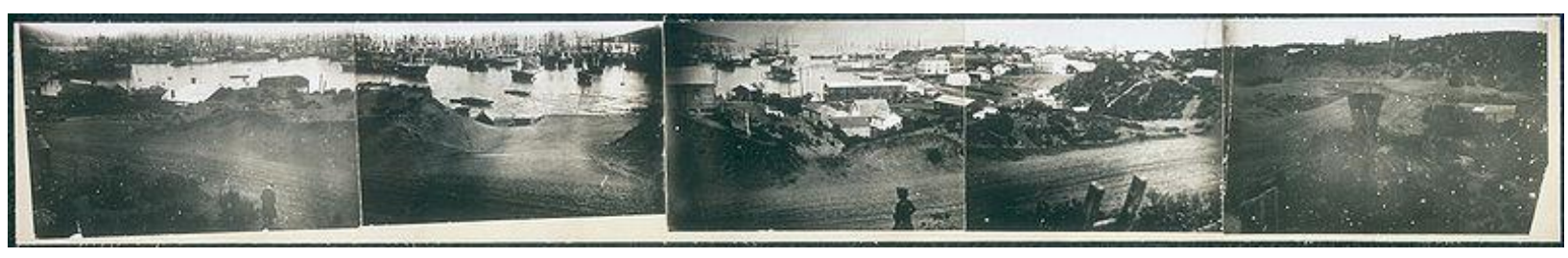

Figura 1. Panorámica de San Francisco por el fotógrafo Martin Behrmanx en 1851, recuperado de esacademic.com.

Siguiendo el desarrollo de la fotografía en el mundo, llegan las películas flexibles en 1888, la fotografía panorámica fue revolucionando, donde esta no depende del fotógrafo como pretende hacer ver el manual o protocolo de la FGN de Colombia, si no que este formato gráfico es estrictamente inherente de la cámara, en sus inicios se empezó con las cámaras GonderPanoramic, Cylindrograph, Pantascopic y Cyclo-Pan, son algunos ejemplos de cámaras fotográficas de la época.

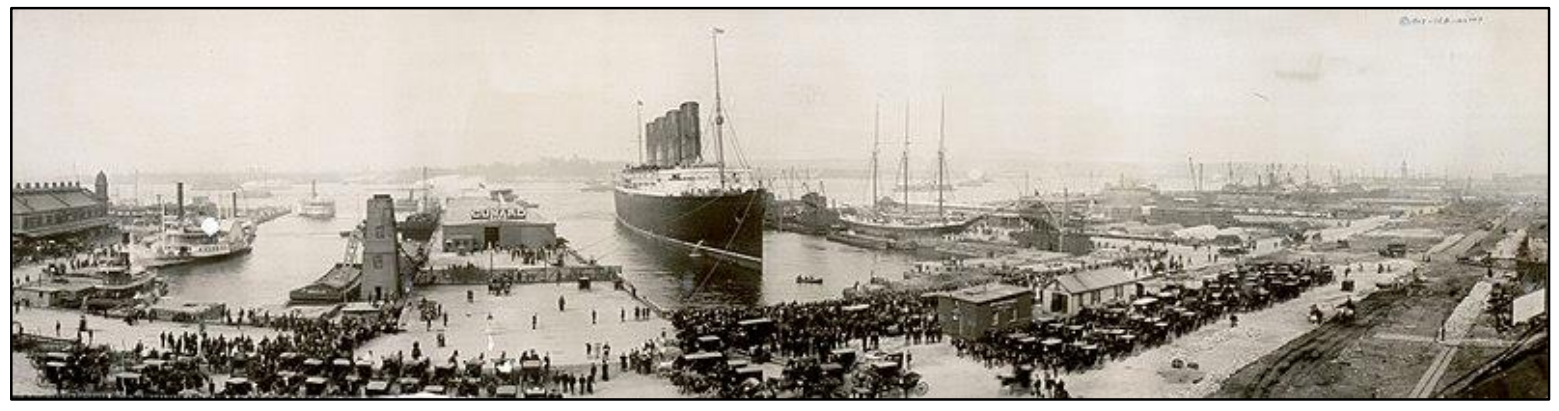

Figura 2. El transatlántico RMS Lusitania en el puerto de Nueva York, durante su viaje inaugural en 1907. recuperado de wikiwand.com.

En la actualidad en el campo forense podemos hablar de fotografías panorámicas cuando cumplan con ciertos principios técnicos, las cuales imperan en poseer un formato de salida gráfico mucho más largo que ancho y que cubran un ángulo horizontal entre $90^{\circ}$ $180^{\circ}$ y $360^{\circ}$ que pueden ser lineales o esféricas, estáticas o dinámicas.

Concepto correcto de toma panorámica: según... (ORTEGA, 2013) “La fotografía panorámica es una técnica de la fotografía (plano visual), en la cual se utilizan 
software y/o equipos especializados que capturan imágenes con puntos de vista alargados que cumplan con un ángulo horizontal entre $90^{\circ}-180^{\circ}$ a $360^{\circ}$ que pueden tomas ser lineales o esféricas, estáticas o dinámicas. Se conoce también como fotografía de amplio formato, son tomas globales (amplitud de la zona horizontal y reducción de la vertical) a larga distancia, que se usan con el objeto de mostrar el aspecto general del lugar y los EMP Y/O EF como se encuentran en su posición final.

En un segundo planteamiento de revisión de los protocolos forenses de fotografía en Colombia se resulta un error común de algunos funcionarios de policía judicial en Colombia, que solo describen determinada evidencia en un contexto subjetivo en el lugar de los hechos; en muchos procedimientos de policía judicial se relacionan en los informes ejecutivos, reportes de iniciación de caso, actas de primer respondiente e informes de policía judicial, pero no se fijan fotográficamente y en muchos casos, ni siquiera la fijan de forma ortométrica. Siendo completamente necesario, no solo la ubicación espacial de la EF, sino que la documentación fotográfica que demuestra la relación de espacio, tiempo y modo. Considerando además que escasos procedimientos de documentación fotográfica o videografíca de la autoridad competente en Colombia, cuentan con metadatos fotográficos, ni con una correcta metodología de organización y descripción de imagen aún bajo los desactualizados e imprecisos protocolos forenses de fotografía de la FGN-Colombia, por ello se consultan fuentes privadas que permiten tener un panorama más técnico en la información fotográfica forense.

En el protocolo interno de la UIFCP se relaciona un orden y técnica especifica en la descripción de imágenes utilizadas en un informe fotográfico forense, las cuales permiten una comprensión más clara y objetiva de lo que se desea mostrar en las tomas fotografías utilizadas. Este protocolo privado forense recomienda en los pies de foto: Número de imagen, fuente o autor, plano visual, sentido de toma (NSEW), referencia espacial o coordenadas geográficas, ángulo horizontal de toma, distancia horizontal y/o vertical de toma, descripción de la imagen. Otro de los aportes que trata este protocolo es el manejo de información videográfica, donde se relacionan los planos visuales como un aspecto técnico diferente a los movimientos de lente y cámara, entre ellos:

Planos visuales: plano general, plano medio, primer plano, primerísimos planos, close up, plano secuencia.

Movimientos de cámara: paneo, tilt, zoom in, zoom out, traveling, picado, contrapicado, dolly aut, dolly in, cámara subjetiva.

Por último rescatamos en la fotografía forense moderna el uso de nuevas tecnologías y técnicas que se emplean en los procesos técnicos forenses, con herramientas como drones, cámaras multi espectrales, infrarrojas, térmicas entre otras y con técnicas que van desde la generación de modelo panorámicos $360^{\circ}$ hasta realidad aumentada; pasando por fotogrametría aérea y terrestre, luces forenses, edición de imagen para animación 3D, fotografía nocturna no contaminada con luz artificial (flash), foto recreación 3D, análisis de colorimetría entre otras modernas técnicas aplicadas al ámbito forense; lo anterior con un común denominador y es el manejo de metadatos y salida de crudos. 


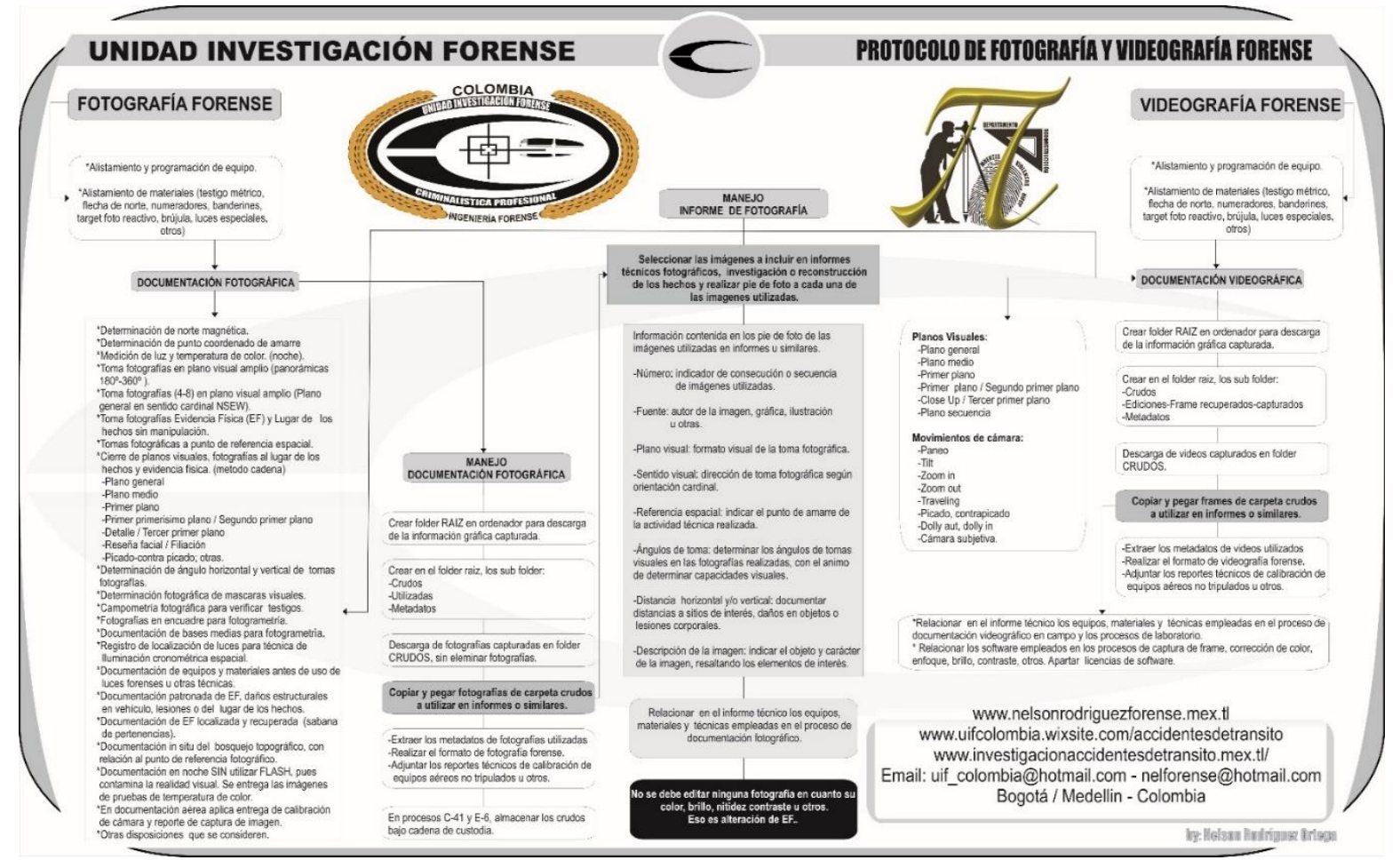

Los soportes crudos u originales de la documentación fotográfica no deben ser contaminados y mucho menos editados, por ello los metadatos que son un conjunto de atributos o elementos necesarios para describir e identificar la autenticidad y manejo de un recurso digital determinado, permiten dar una intachable calidad probatoria a la información digital que orientada con el manejo documental de recolección y entrega de información fotográfica y videográfica permiten mejores enfoques reconstructivos forenses y toma de decisiones administrativas o judiciales.

\section{Discusión}

Ahora partiendo de procedimientos de documentación de EF observados en diferentes procesos investigativos penales en Colombia, Ecuador, Panamá, Perú, otros; no se cumple en muchos casos con la entrega de los registros fotográficos con cadena de custodia, con sus respectivos metadatos o ficha técnica de fotografía, se observan los pie de foto de las imágenes que soportan los informes con errores de manejo de conceptos como el expuesto panorámica. Pero mucho más complejo y grave, es que en procesos penales conocidos por la UIFCP se observó que la EF no es documentada técnicamente en el lugar de los hechos, dejando en el limbo la relación de espacio, tiempo y modo frente al hecho investigado.

Según (FGN, 2016), Inspección del Lugar de los Hechos artículo 213 del C.P.P. El análisis y observación detallada minuciosa y metódica del Lugar de los Hechos, permite descubrir, identificar, fijar, recoger y embalar técnicamente los EMP y EF, que permiten demostrar la ocurrencia de la conducta punible y establecer nexos y relaciones entre estos 
y el autor (es) o partícipe (s) del ilícito... Cada EMP y EF, será manejado bajo los procedimientos de cadena de custodia para evitar la suplantación o alteración del mismo; es importante señalar que, en todos los casos, en Formato Pro forma el servidor de Policía Judicial certifica bajo la gravedad del juramento, que ha corroborado la corrección de los procedimientos de recolección, embalaje y conservación de los mismos.

Ahora en este orden de ideas, partiendo de la premisa del estado del arte en Colombia, donde los protocolos de fotografía en materia de muertes violentas y casos contrarios a la ley son realizados por la Fiscalía General de la Nación FGN (2005), documentos que no están actualizados, no son específicos e ilustrativos; la discusión y muy sería problemática radica en el siguiente cuestionamiento:

¿El ente estatal FGN u otros, aceptarían y adoptarían las investigaciones, aportes y los conocimientos dispuestos por laboratorios privados o instituciones educativas para el mejoramiento de las ciencias forenses y una mejor administración de justicia??

Como estrategia y opinión personal al respecto, lo primero es promulgar este documento de manera oficial e impresa, permitiendo a los interesados en el tema forense conocer de procedimientos adecuados de fijación de EF y/o EMP, motivando a las instituciones estatales al mejoramiento de sus protocolos, utilizando incluso las investigaciones de laboratorios de reconstrucción de muertes violentas privados.

\section{Conclusiones}

- Se logró presentar el esquema gráfico de un protocolo técnico de fotografía aplicado a la fijación de EF y/o EMP y manejo de la información gráfica, una vez es recolectada esta información en el lugar de los hechos y llevada al laboratorio o escritorio, relacionando los procedimientos a seguir con la información fotográfica recaudada.

- Se cumplió con el objetivo de realizar la descripción de al menos uno de los conceptos errados contenidos en los manuales de fotografía forenses de la FGN, ilustrando gráficamente y describiendo los precedentes reales del concepto de fotografía panorámica, además de realizar consideraciones a tener en cuenta al emplear este concepto de plano visual para la fijación de evidencia física en el lugar de los hechos.

- Se expuso de forma respetuosa crítica pero constructiva, una comparación entre los protocolos de documentación fotográfica de la FGN y una institución forense privada, donde la manera técnica actual de documentación fotográfica forense utilizada por laboratorios forenses privados, genera un mayor aporte científico al área técnica de fotografía y videografía, frente al Manual Único de Criminalística de Colombia.

- Se consiguió en el desarrollo del proyecto investigativo de fotografía forense, definir procesos, metodologías, técnicas, pasos y herramientas que nunca antes han estado descritas en algún manual, texto u otro documento, citando nuevos conceptos de fotografía forense utilizados en la investigación criminal, y que no se ven reflejados en los protocolos de fotografía forense de la FNG. 
- Haciendo de uso del instructivo de documentación fotográfica forense de la UIFCP, se considera como una herramienta útil para la sociedad interesada en la investigación científica de fotografía y videografía aplicada a la reconstrucción de muertes violentas. Abarcando incluso las consideraciones a tener en cuenta en la recolección de información en terreno o campo, así como lo requerido en el proceso de manejo de datos crudos a informes de técnicos forenses.

\section{Agradecimientos}

Gracias a mi universidad Católica de Cuenca, gracias a todos ustedes; fueron los responsables de realizar su gran aporte, que el día de hoy se ve reflejado en un proceso de investigación científica contribuyente directo al desarrollo de las ciencias forenses de Ecuador y Latinoamérica. El autor desea expresar su gratitud a los muchos estudiosos que, a lo largo de más de un siglo, han descubierto, descifrado, traducido y explicado algunos procedimientos técnicos forenses, cuya cortesía el autor ha podido acceder a las evidencias textuales y gráficas en las que se basa este artículo.

\section{Referencias bibliográficas.}

Diccionario real academia española, 2. (s.f.). Diccionario real academia española. Recuperado el 16 de junio de 2018.

Ingenio Libre,. Revista de la facultad de ingenierìa de la universidad Libre.

Diccionario de la real academia española, 2. (s.f.). Recuperado el 16 de junio de 2018. FGN. (2016). Manual policia judicial. Bogotá.: fiscalia general de la nación. (2005).

Johnson, R. Barry (2008). Correctly making panoramic imagery and the meaning of optical center. SPIE Proc. Vol. 7060.

Manual Procedimiento criminalistica FGN. Bogota, cundinamarca, colombia: isbn95897762-05.

Meers, Nick (2003). The World of Panoramic Photography. Rotovision. ISBN 2-88046692-X.

Ortega, Nelson (2016). Manual de topografia forense aplicado a la investigacion y reconstruccion de muertes violentas, Universidad Distrital Fransisco Jose De Caldas. Bogotá-Colombia.

Rodriguez, Nelson (Octubre de 2013). Topografía aplicada a la reconstrucción de accidentes de transito. Bogotá, Colombia.

Rodolfo Torregrosa Jiménez, ABC del Articulo Cintifico, Universidad Libre, BogotáColombia 2016.

Sergio Roberto Matis Camargo (2011), Normas para la postulaciòn y publicacion de articulos, Universdad Libre, Facultad de Derecho 6 de Diciembre de 2011.

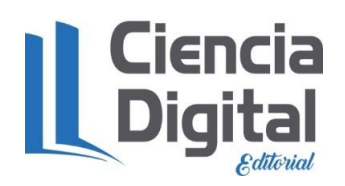


Para citar el artículo indexado.

Rodríguez F. (2019) Fotografía forense de los protocolos de fotografía forense Riobamba, provincia de Chimborazo-Ecuador. Revista electrónica Ciencia Digital 3(1.1), 189-198. Recuperado desde: http://cienciadigital.org/revistacienciadigital2/index.php/CienciaDigital/article/view/369/787

\section{¿Ciencia}

El artículo que se publica es de exclusiva responsabilidad de los autores y no necesariamente reflejan el pensamiento de la Revista Ciencia Digital.

El articulo queda en propiedad de la revista y, por tanto, su publicación parcial y/o total en otro medio tiene que ser autorizado por el director de la Revista Ciencia Digital.
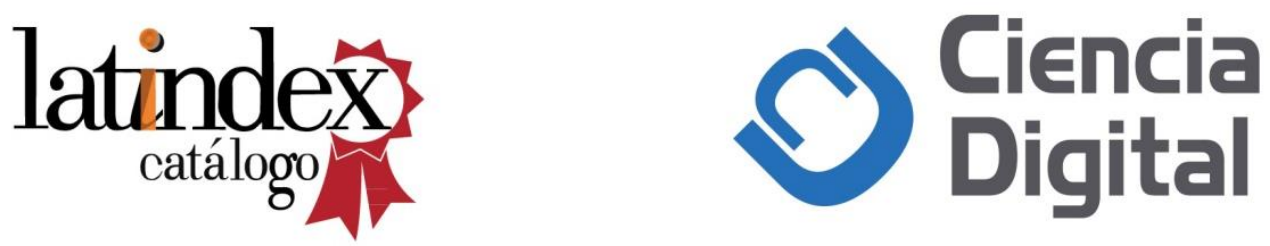